\title{
Bilateral visual loss caused by an intracranial aneurysm
}

\author{
Changseok Lee MSc, Anuradha Mishra MD MSHPEd
}

Cite as: CMAJ 2020 July 27;192:E860. doi: 10.1503/cmaj.191477

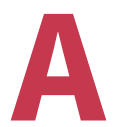

48-year-old woman was referred to the ophthalmology department with a 6-month history of blurry vision in her left eye. Her visual acuity was $6 / 6$ in her right eye and $6 / 18$ in her left eye using the Snellen chart, with decreased colour vision in her left eye.

We performed the swinging flashlight test, which showed a left relative afferent pupillary defect. Her left optic nerve showed temporal pallor. We conducted an automated Humphrey visual field test and found a superotemporal defect and diffuse vision loss in her right and left eyes, respectively (Appendix 1, Supplementary Figure 1, available at www.cmaj.ca/lookup/suppl/ doi:10.1503/cmaj.191477/-/DC1). Our patient underwent urgent magnetic resonance imaging that showed an aneurysm $(1.6 \mathrm{~cm}$ in diameter) in the suprasellar region arising from the left paraophthalmic artery (Figure $1 \mathrm{~A}$ ), which impinged on the proximal aspect of the left pre-chiasmatic optic nerve. We referred our patient to neurosurgery, and she underwent urgent endovascular coiling of the aneurysm (Figure 1B). Her vision has stabilized postoperatively with residual field defects.

Aneurysms of the paraophthalmic artery are uncommon, representing about $5 \%$ of all cerebral aneurysms, and are typically detected because of progressive visual defects. ${ }^{1}$ The differential diagnosis for a junctional lesion (i.e., a lesion occurring at the junction of the optic chiasm and optic nerve) includes neoplasms such as pituitary adenoma, meningioma, craniopharyngioma and gliomas, and aneurysms of the circle of Willis. Less common causes include inflammation (e.g., sarcoidosis or multiple sclerosis), trauma and radiation necrosis. ${ }^{2}$

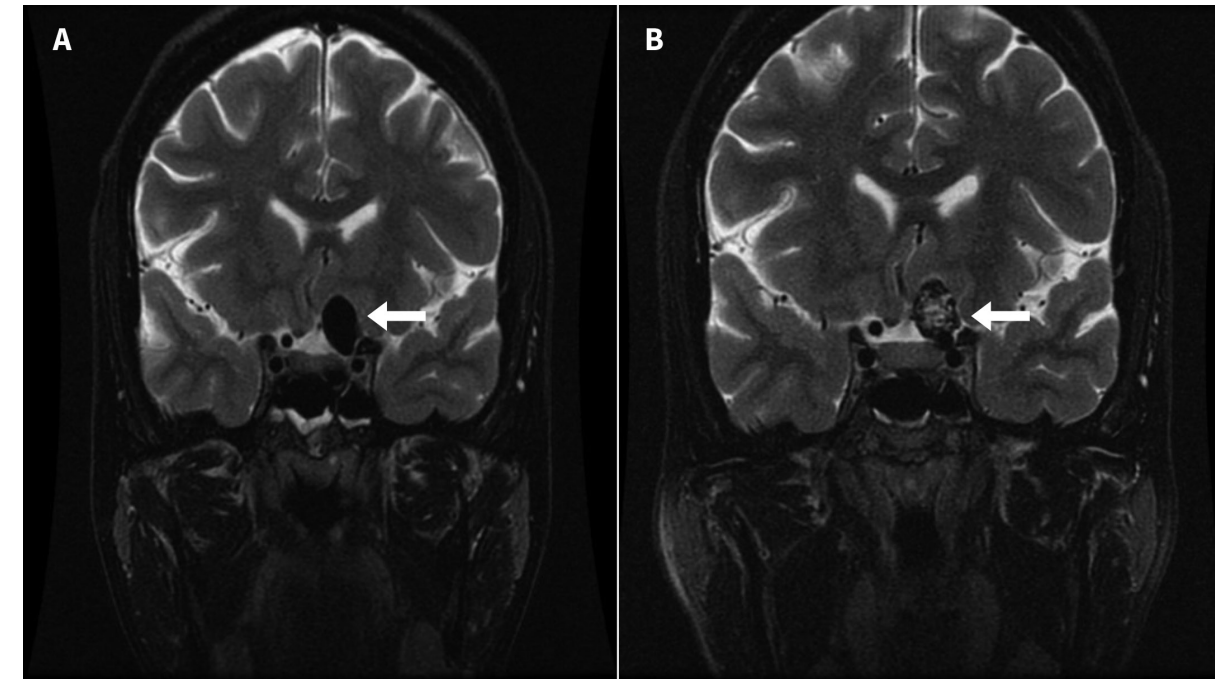

Figure 1: Magnetic resonance imaging (coronal $T_{2}$-weighted with fat suppression) showing an intracranial aneurysm $\left(1.6 \times 1.0 \times 0.9 \mathrm{~cm}^{3}\right)$ in the left paraophthalmic artery in the left suprasellar region (A) before and (B) after endovascular coiling (arrows).

In our patient, the presence of a relative afferent pupillary defect was an important indicator of optic nerve dysfunction, and visual field examinations helped localize the pathology along the visual pathway. Also known as a Marcus Gunn pupil, relative afferent pupillary defect can be evoked with the swinging flashlight test. The affected pupil dilates when the light is swung from the unaffected to the affected eye. With minimal equipment, primary care physicians can assess ocular symptoms using basic ophthalmic examinations including visual acuity, visual fields by confrontation and pupillary function to localize pathology and guide further management.

\section{References}

1. Jeong Y-G, Jung Y-T, Kim M-S, et al. Size and location of ruptured intracranial aneurysms. J Korean Neurosurg Soc 2009;45:11-5.

2. Menjot de Champfleur N, Menjot de Champfleur S, Galanaud D, et al. Imaging of the optic chiasm and retrochiasmal visual pathways. Diagn Interv Imaging 2013;94:957-71.

\footnotetext{
Competing interests: None delcared.

This article has been peer reviewed

The authors have obtained patient consent.

Affiliations: Dalhousie Medical School (Lee); Department of Ophthalmology and Vision Sciences (Mishra), Dalhousie University, Halifax, NS
}

Correspondence to: Anuradha Mishra, Anuradha.Mishra@Dal.ca 